\title{
Maintaining basic state functions and service delivery during escalating crises
}

Siân Herbert

GSDRC \& K4D, University of Birmingham

17 May 2021

\section{Question}

- What evidence is there for what works to maintain essential state functions and basic service delivery in escalating conflict situations? Focus on modalities and lessons from contexts like Afghanistan, Yemen, Somalia, and Syria.

\section{Contents}

1. Overview

2. The development, humanitarian and peacebuilding nexus

3. A new fragile states paradigm?

4. The resilience agenda

5. Prevention

6. References

The K4D helpdesk service provides brief summaries of current research, evidence, and lessons learned. Helpdesk reports are not rigorous or systematic reviews; they are intended to provide an introduction to the most important evidence related to a research question. They draw on a rapid deskbased review of published literature and consultation with subject specialists. 


\section{Overview}

This rapid literature review explores how to maintain essential state functions and basic service delivery during escalating conflict situations. It draws on literatures and ideas from various overlapping agendas including: development and humanitarian nexus; development, humanitarian and peacebuilding nexus (the "triple nexus"); fragile states; state-building; conflict sensitivity; resilience; and conflict prevention and early warning. There has been extensive exploration of these ideas over the past decades: as the international development agenda has increasingly focussed on the needs of fragile and conflict affected contexts (FCAS); as violent conflicts have become more complex and protracted; as the global share of poverty has become increasingly concentrated in FCAS highlighting the need to combine humanitarian crisis strategies with longer-term development strategies; as threats emanating from FCAS increasingly affect countries beyond those states and regions e.g. through serious and organised crime (SOC) networks, migration, terrorism, etc; and as global trends like climate change and demographic shifts create new stresses, opportunities, and risks (OECD, 2020; Ingram \& Papoulidis, 2018; United Nations (UN) \& World Bank, 2018; Ozano \& Martineau, 2018).

Yet despite these extensive debates, the literature base is limited in various ways, e.g. there are limited practical examples of when humanitarian and development principles have been bridged in practice (Ozano \& Martineau, 2018, p.2), and there is limited understanding of the variability of outcomes across different contexts - e.g. of service delivery in violence-affected contexts (World Bank, 2017). Much of the current literature focuses on the how (i.e. the strategies and modalities for engagement), and not on the what (i.e. thematic areas to prioritise), possibly as a response to calls for programming to be better context derived.

Some of the key lessons from these agendas have remained steadfast, and gained traction, over time - such as the importance of context specificity and conflict sensitivity in responses, and the need for better coordination and integration to overcome silos between development, humanitarian and development actors. While there are also evolutions and innovations in the agendas, as lessons emerge, and as political agendas and interests change in the host and donor countries - such as more recent trends of resilience thinking, complexity, and adaptive programming. The FCAS group is fairly broad, and this query focusses on countries that have particularly protracted contexts, including Afghanistan, Yemen, Somalia, and Syria, as well as including higher-level analysis on broad principles for engagement in FCAS. Overarchingly, these contexts are extremely complex, and while common trends can be identified, generalisable lessons are much more difficult to discern (United Nations \& World Bank, 2018). The literature used for this query is predominantly from practitioner and policy publishers, due to the applied nature of the question. As this question covers such a broad range of issues, this query cannot be considered conclusive, but is instead illustrative of some of the main findings, lessons, and trends from recent debates.

\section{Key findings}

The development, humanitarian and peacebuilding nexus - Debates about how to better connect activities across these sectors have emerged since the 1990s and continue to expand, in-line with broader changes in international development and foreign policy agendas. In situations of escalating conflict and fragility, development programming is typically diminished in favour of humanitarian programming, yet new debates emphasise the importance of prioritising 
"prevention always, development when possible and humanitarian action when necessary" (OECD, 2020, p.17). International actors (particularly the UN) are responding to this age-old challenge of coordination and integration through piloting a new approach - the 'New Way of Working' - and through frameworks to coordinate aid, strategy, resource mobilisation, and programming with other actors (e.g. country platforms, joint assessments; compacts; etc). Core lessons emerging from the use of country platforms and compacts includes the importance of: context; country ownership and participation; good understanding of (national, sub-national and international) capacities; support for compacts from leadership; balancing prioritisation and focus with vision and achievability; specific, concrete, monitorable and balanced commitments; twosided mutual accountability; the inclusion of specific actions in compact strategies; and understanding that while compacts generally improve coordination, it can come with high transaction costs (Manuel, McKechnie, Wilson \& das Pradhan-Blach, 2017, p.12). Specific lessons from Afghanistan and Somalia are detailed in section 2.

A new fragile states paradigm? The fragile states agenda is undergoing what looks to be a paradigm shift to include ideas of resilience, risk and vulnerabilities; prevention; complexity; and adaptive management. A key aspect of this is the acknowledgment of the centrality of politics - a key response to the critique that the fragile states agenda was too technocratic.

The resilience agenda - Resilience thinking is now a key framework through which to understand: why some societies are particularly vulnerable to violence (the so-called fragility-toresilience paradigm); the complex, multiple connections between conflict, crises, disasters, and poverty; the importance of risk analysis and preparedness to mitigate against vulnerabilities and to build on already existing capacities; the importance of social capital and social cohesion in FCAS; and the importance of including local communities in peacebuilding and development processes. Yet while resilience (and 'building back better') is increasingly referred to in policy discussions and practices, important challenges remain in defining, understanding, analysing, and operationalising this framework in politically and technically feasible ways.

Prevention - Conflict prevention and stabilisation approaches are increasingly integrated with this resilience framework, e.g. with both seeking to identify risks and reduce vulnerabilities to conflict and crisis. An important element of the prevention agenda is the need for mechanisms to allow greater synergies among diplomacy and mediation, security, and development activities. Lessons include: sustaining prevention activities over time to address structural issues, to strengthen institutions, and to adapt incentives; ensuring prevention activities are inclusive and build broad partnerships; and ensuring prevention activities proactively and directly target patterns of exclusion and institutional weaknesses that increase risks (UN \& World Bank, 2018, p.xxvi).

\section{The development, humanitarian and peacebuilding nexus}

Debates about the relationship between humanitarian assistance and development aid emerged in the 1990s, and has continued to expand, in-line with broader changes in the international development agenda, moving from a predominant focus on aid and poverty to also include peacebuilding and state-building, fragile states, stabilisation and, more recently, radicalisation and extremism (Haider, 2014; Hinds, 2015; Herbert, 2017). The "triple nexus" concept now refers to the relationship between development, humanitarian and peacebuilding. 
In situations of escalating conflict and fragility, development programming is typically diminished in favour of humanitarian programming (FAO, DI \& NRC, 2021, p.vi) - this has broad impacts, e.g. on the type of modalities used to deliver programming (e.g. less budget support and more food aid), the type of actors involved in delivery (e.g. less engagement with the state, and more engagement with multilateral platforms and international non-governmental organisations), and other aspects like the thematic areas of programming, ${ }^{1}$ strategy, priorities, principles, cultures, mandates, timescales for engagement, etc (Ozano \& Martineau, 2018; Hinds, 2014). As these policy debates evolve, strategies such as resilience and prevention have been proposed to ensure that these sectors are bridged, and that FCAS are not left behind. The OECD's (2020, p.17) flagship annual report on fragile states argues that engagement in fragile contexts should "prioritise prevention always, development when possible and humanitarian action when necessary".

There is widespread acknowledgement of the need for better coordination between these areas to ensure e.g. that needs are met, and there are not gaps in programming and funding, that synergies are made across short-term humanitarian and longer-term development programming, and that programming in one area does not undermine programming in another. E.g. it is seen as critical for contexts like Somalia - that are heavily dependent on humanitarian assistance - to maintain development gains that have been achieved in previous years (Medinilla, et al., 2019). There has also been a recognition that humanitarian, development and security needs are inter-related, self-reinforcing and often occur concurrently, thus humanitarian, development and peace programming needs to be simultaneous, not sequenced (Herbert, 2014; FAO, DI \& NRC, 2021, p.vii).

Yet this is not without risks, linking development, security, with humanitarian work can undermine humanitarian principles of neutrality and independence, can undermine the responsiveness and timeliness of emergency services, and pursuing principles of government ownership can mean working with agencies and actors that are perceived as illegitimate (Ozano \& Martineau, 2018; Stoddard \& Harmer, 2005). "Engaging humanitarian actors in discussions early on may help alleviate concerns and encourage productive communication", find Ozano \& Martineau (2018, p.2).

Some criticise the merging of agendas as the "radicalisation of development", while others argue it reflects the reality of doing development in FCAS (Duffield, 2014; Barakat \& Waldman, 2013). This broadening, in specific contexts, has brought together ambitious and

${ }^{1}$ State-building domains in FCAS are often conceptualised into hierarchical categories of (Herbert, 2014; DFID, 2009):

Essential state functions (also called 'core' or 'survival' state functions, or constitutive domains), which includes: the political settlement; security - monopoly of violence, justice and the rule of law; and basic administrative and fiscal capacity; and

- $\quad$ Expected functions (also known as 'output domains'), which includes: service delivery (health, education, water), infrastructure; economic management; employment programmes and job creation; personal safety and access to justice (beyond the basic level provided in state survival); social protection/safety nets; anti-corruption measures; and voice and accountability (e.g. fair elections, free media).

Also see this useful guidance by USIP on what "stable governance" is, and key considerations for determining core functions of the state - https://www.usip.org/guiding-principles-stabilization-and-reconstruction-the-webversion/stable-governance 
sometimes contradictory goals that can undermine what many people still consider to be the primary purpose of aid: poverty reduction.

In order to mitigate against the negative tendencies of securitisation, Saferworld (2011, p.11) recommends a further "developmental-isation' of the security discourse", with the following steps:

- Take an inclusive approach, based on human security, prioritising "the needs of people and the state, but always with an ultimate focus on the security of poor, vulnerable and marginalised groups".

- Make sure reforms are "locally-owned, informed by a good understanding of realities on the ground, and involve the meaningful participation of those they affect".

- Always begin with the context, as challenges and needs vary according to place and time, and as it is more effective to support and build on what already exists.

- Co-ordinate and even integrate, but do not subsume development into defence and foreign policy. Coherent development, diplomatic, and defence policy should be aligned according to common goals and based on a shared understanding of the context, but should not be subsumed.

The use and predominance of humanitarian or development systems and actors reflects the local context, but also the interests and incentives of international actors - e.g. competition between aid actors for dominance over agendas and/or budgets can disincentivise integration and effective cooperation (Medinilla, et al., 2019). This may be further complicated by the increased role played by non-DAC donors as they tend to engage much less in traditional multilateral coordinating mechanisms (Medinilla, et al., 2019). Other challenges include conceptual, institutional and strategic gaps between the different sectors/actors; lack of capacity and expertise to coordinate; lack of flexibility in funding arrangements; and funding gaps (Hinds, 2015). Notably, funding limitations are likely to become even more challenging in the current context of COVID-19, as COVID-19 interventions and its indirect impacts strain local livelihoods, domestic resources for development, broader economic development trends, and international development budgets (Herbert \& Marquette, 2021).

The need for better coordination and integration across development, humanitarian and peacebuilding silos remains a crucial and "age-old challenge" (Medinilla, Shiferaw \& Veron, 2019). E.g. a review of the literature on health financing in FCAS found that the most discussed topic is aid coordination, and that "despite efforts to coordinate approaches across humanitarian and developmental settings, the literature remains distinct between them" (Bertone, Jowett, Dale \& Witter, 2019). While multilateral organisations and bilateral agencies have made substantial policy-level advances in this thinking, practical implementation remains challenging (Medinilla, et al., 2019; FAO, DI \& NRC, 2021).

\section{New Way of Working (NWOW) agenda to address the triple nexus}

The current UN agenda that addresses this nexus is called the 'New Way of Working' (NWOW), which is a "method of work" that connects to the Sustainable Development Goals (SDGs) and draws on the G7+ New Deal's principles (International Council of 
Voluntary Agencies (ICVA), 2017, p.1). It "calls on humanitarian and development actors to work collaboratively together, based on their comparative advantages, towards 'collective outcomes' that reduce need, risk and vulnerability over multiple years" (UN, n.d.), particularly in protracted crises. Key elements of the method are its focus on: collective outcomes, comparative advantage, and context specificity. It highlights that the approach requires changes in analysis, planning, programming, leadership and financing (UNOCHA, 2018, p.1). While this agenda may not seem that new, ICVA (2017) identifies new elements as the focus on shared goals ("collective outcomes") over several years. They also highlight how it has evolved as a response to calls for a more coherent UN, and the World Bank is stepping up its work on fragility and conflict, and as there is a renewed global impetus to address the humanitarian-development gap (ICVA, 2017).

In deciding who should be involved in designing the strategy, it highlights asking (UNOCHA, 2018, p.4):

1. What is the nature of the crisis? (e.g. conflict, disaster)

2. What is the level of violence in cases of armed conflict? (e.g. high intensity, low intensity)

3. Is there an emerging or established political settlement?

4. What is the role and capacity of the government?

It emphases the need to include consultation with affected communities and provisions for civil society actors to participate (UNOCHA, 2018, p.4).

In how to define and articulate collective outcomes, it highlights (UNOCHA, 2018, p.4):

1. Carry-out a joint humanitarian-development analysis of needs, vulnerabilities and risk, including the causes and impacts of a crisis. Then determine and prioritise a small number of areas that require simultaneous humanitarian and development action. All sources of data should be pooled.

2. Determine the timeframe for work (ideally, between 3-5 years), taking into account other relevant planning timeframes.

3. Based on a review of relevant national SDG objectives, determine what target would be appropriate for each collective outcome.

In how to operationalise the outcomes, it highlights (UNOCHA, 2018, p.4-5):

1. Bring together humanitarian-development nexus partners based on comparative advantages.

2. Work backwards from each outcome to determine the activities required to achieve it.

3. Identify which response priorities and activities are humanitarian and which are development-related, and which organizations can contribute particular programming to an identified collective outcome.

4. Think through the sequencing and layering of short-, medium- and longer-term interventions according to people's needs and vulnerabilities over the timeframe.

5. Incorporate response priorities and activities in the relevant planning frameworks (e.g. humanitarian, development, government). If appropriate/useful, in a joint document. 
6. Discuss the conditions needed for the interventions to be effective and actions to reach these conditions (e.g. increased government capacity, social safety net programmes).

7. Secure flexible and predictable financing aimed at financing outcomes (not activities), and resourcing the actors required to achieve the collective outcome (e.g. UN entities, civil society, government, etc)

8. Develop a results-based framework for collective outcomes that is aligned with relevant planning frameworks. The collective results-based framework could become the joint accountability tool for humanitarian and development partners.

\section{NWOW in practice through the Deliver Accelerated Results Effectively and Sustainably (DARES) collaboration}

The Deliver Accelerated Results Effectively and Sustainably (DARES) (2017) collaboration brings together four organisations - UNICEF, World Bank, World Food Programme (WFP) and the World Health Organisation (WHO) - under an operational framework that builds on each organisation's comparative advantages, and under a strategy emphasising prevention. The DARES (2017) approach is used in Yemen, and is also being piloted in a number of other countries where governments are non-functional, or are not in control of large parts of their respective countries, (e.g. Yemen, Somalia and Libya), and/or where a direct implementation model may be possible (i.e. a UN agency receiving IDA 18 funding, or from a Multi-Donor Trust Fund), and/or countries where the government has limited capacity (e.g. Central African Republic and Haiti).

\section{Frameworks for cooperation}

\section{Donors in FCAS and partner governments are increasingly using frameworks to} coordinate aid, strategy, resource mobilisation, and programming with other actors, e.g. including country platforms, joint assessments; ${ }^{2}$ compacts; peace agreements; financial frameworks, ${ }^{3}$ and donor conferences. While this has mostly been led by multilateral organisations (e.g. UN, World Bank), it is a more recent trend in bilateral donors' approaches (Herbert, 2017). And there is increasing impetus for country platforms to be used more strategically in FCAS, building on the work of the New Deal, and now continuing into what appears to be a new paradigm based on a fragility-to-resilience framing (Ingram \& Papoulidis, 2018; Papoulidis, 2020a). "Country platforms must ultimately become a vehicle for more collaborative, resilient, adaptive and scalable approaches to help fragile states", argues Papoulidis (2020a). Papoulidis (2020a) identifies a common ("aspirational") model that many country platforms have:

- "A high-level steering group led by Presidents or Prime-Ministers and comprised of senior multilateral and bilateral donor officials, implementing partners and representatives of civil society to help contribute to a national development plan, collective sense-making of the context, resource mobilization, mutual accountability and troubleshooting.

\footnotetext{
${ }^{2}$ E.g. the Recovery and Peace-Building Assessments (RPBAs), Post-Conflict (or Crisis) Needs Assessment (PCNA)

${ }^{3}$ E.g. UN-led Integrated National Financial Frameworks (INFF)
} 
- A sector-level led by government ministers who assemble their own core sector groups of technical experts, operational partners and societal stakeholders to determine sector policy, resource flows and "who's doing what where."

- A secretariat-level led by the Ministry of Planning and staffed by domestic and international experts with analytic, convening and troubleshooting roles to administer to the functioning of the steering and sector levels and facilitate achievement of overall development goals".

Two graphic depictions of the structures of country platforms in Somalia and Central Africa Republic are found in Figures 1 and 2 respectfully (Papoulidis, 2020a).

See: Figure 1: Somalia's Country Platform (Papoulidis, 2020a), http://www.globaldeliveryinitiative.org/blogs/country-platforms-fragile-states-new-pathdevelopment-cooperation

See: Figure 2: Proposed Country Platform for the Central African Republic for its National Recovery and Peacebuilding Plan (RCPCA) and Mutual Commitment Framework (CEMRCA) (Government of Central African Republic, 2016 p.5, https://documents1.worldbank.org/curated/en/817461516999933538/pdf/122994-WP-PUBLICCAR-RPBA.pdf; Papoulidis, 2020a, http://www.globaldeliveryinitiative.org/blogs/countryplatforms-fragile-states-new-path-development-cooperation)

These frameworks "can help drive the significant change needed in the interaction and coherence of the security, political/diplomatic and humanitarian and development systems, helping to accelerate the reengagement of the private sector" (Thier, 2019, p.1). Yet although country platforms (under their various names) have been used for over two decades, they are "among the least examined and refined elements of development policy and practice" (Papoulidis, 2020b). Drawing on lessons from 10 years of compacts, ${ }^{4}$ Manuel, et al. (2017) highlight:

- The compact must fit the country context;

- Country ownership and participation in designing the compact increases the chance of success;

- The level of national, sub-national and international capacities to manage and implement should be factored into compact design;

- Compacts need to be understood and supported by the leadership, the legislature and other key locations of power;

- Prioritisation and focus that balances vision and achievability is key;

- Compact commitments and benchmarks should be specific, concrete, monitorable and balanced;

- Mutual accountability needs to be two-sided;

\footnotetext{
${ }^{4}$ In Liberia, Afghanistan, Iraq, Democratic Republic of the Congo (DRC), Timor-Leste, South Sudan, Rwanda Yemen, Afghanistan, and Somalia,
} 
- Specific actions and support to strengthen government institutional effectiveness should be included, with the focus of effort onto compact priority areas synchronised with the approved plans of government; and

- While compacts generally improve coordination, this can come with high transaction costs

Lessons from Afghanistan's first New Deal-type compact - agreed in 2006 - found that the compact "lacked prioritisation or focus, partly because the Afghan Cabinet was divided and each ministry, development agency and donor wanted its programme included in the Compact to safeguard its own funding", found Manuel, et al. (2017, p.12). Its second compact (the Tokyo Mutual Accountability Framework for Afghanistan, 2012) addressed some of these problems, in being more selective than the previous compact, but yet it then faced criticism "for leaving out key determinants of stability and poverty reduction in Afghanistan, such as private sector development and employment, justice and limiting corruption" (Manuel, et al., 2017, p.12).

Somalia's New Deal Compact became its primary framework for aid coordination between development partners and Somalis for prioritisation, sequencing, aid effectiveness and coordination, while the Somalia Development and Reconstruction Facility became the major governance mechanism to coordinate aid around the compact (Hearn, 2016). In an independent review of the New Deal, Hearn (2016) identifies that the compact: lead to a more organised relationship between the international community and the government; was broadly owned and accepted by the government; and expedited a shift in planning and programming, from an exclusive focus on humanitarian action to a wider focus on peacebuilding and state-building. Yet challenges to the success of the compact include: low levels of consultation and adherence to the core principles of the compact; and the rushed development of the compact meant that only symbolic consultations were undertaken with civil society, parliament and sub-national political authorities (Hearn, 2016). Detailed analysis of the compact by Manuel, et al. (2017) identifies areas for new agreements:

- Stronger focus on private sector issues

- Renewed focus on ensuring all efforts are integrated and coherent

- Faster progress on core financial and governance issues - especially on improving PFM coherence and coordination, tackling corruption, prioritising across all sources of finance and agreeing a roadmap for arrears clearance and debt relief.

- Improved consultation processes to ensure the right balance between large consultative groups, supported by much greater investment in the translation of documents and smaller groups for ongoing honest exchange.

\section{Country-led strategies when legitimacy is contested?}

In general, the largest share of development finance in protracted crises is channelled to recipient governments, however, this is complex when the legitimacy of political actors is challenged (e.g. as in Somalia), and where government structures are weak or unresponsive to local populations (Food and Agriculture Organization (FAO), Development Initiatives (DI) \& Norwegian Refugee Council (NRC) (2021)). Particularly in these cases, important entry points emerge around partnerships with local governments, through local governance programmes, and, in some cases, bypassing national ministries (FAO, DI \& NRC, 2021, p.vi; Ozano \& 
Martineau, 2018). Ozano and Martineau (2018, p.3) highlight "the need to identify concepts and methods for working with pluralistic, under-governed, transnational health systems".

\section{A new fragile states paradigm?}

The fragile states agenda has been the dominant framing and forum over the past decade for how international actors can engage in FCAS. Key critiques of that agenda include: that it has favoured: transplanting best-practices from one context to another (the good governance agenda), without sufficient understanding of the context; short-term, uncoordinated, one-off projects rather than sustainable engagement; the promotion of economic growth and poverty eradication over crisis management; and the idea of a fragile/non-fragile binary (Ingram \& Papoulidis, 2018; World Bank, 2017).

In recognition of these limitations, the debates around the fragile states agenda are evolving in various ways, e.g. away from a fragile/non-fragile binary towards a multidimensional understanding of fragility; away from ideas of best practice to a focus on "what works while also recognising what does not work"; away from ad hoc, disjointed investments to country platforms for development cooperation; away from a poverty and growth focus, to a focus on risk and resilience; and new focus areas including: resilience, adaptive development, addressing political problems, collective action, and scaling (Ingram \& Papoulidis, 2018; OECD, 2020; Papoulidis, $2020 \mathrm{~b})$. One of the more recent forums created the five principles of the Bellagio Consensus:

"keeping politics at the centre; local ownership; a transition from donor-led, many priorities to country-led, few priorities; inclusion and engagement from idea to implementation; and confidence-building along the way" (Thier, 2019, p.1).

\section{Centrality of politics}

The importance of acknowledging the centrality of politics in state- and peace-building processes, and the complexity of working politically, is reiterated throughout the literature (e.g. UN \& World Bank, 2017). A key critique of the fragile states agenda is that it represented a technocratic view of such reforms, and this is also a critique levelled at the Millennium Development Goals (MDGs), where discussions about conflict, inequity, or lack of human rights and justice were "conspicuously avoided" (Lindborg, 2017, p.3).

Drawing on fieldwork in Afghanistan, Nepal, and Pakistan on the delivery of health, education, and rural infrastructure services, the World Bank (2017, p.xiv) finds that research and programming needs to go beyond "overly simplistic" classifications of violence, and broad, highlevel principles, to really unpack context specific political economy and violence risks in service delivery. In highlights the importance of understanding the "specific characteristics of political settlements at various levels, the different dimensions of violence, the processes and forms of bargaining and strategies of delivery" to understand better the variation in the success of service delivery programming (World Bank, 2017, p.xvii). Meanwhile, Thier (2019, p.8-9) recommends keeping politics at the centre of programming through:

- Cultivating a vanguard of change in key countries and institutions by making sure there is support for actors in the institutions and systems - local, national and international - that will ultimately be responsible for driving change. This can be done by setting incentives to 
motivate those actors and their institutions, and creating networks to share learning and experience.

- Looking for pivotal moments to make progress on new approaches.

- Setting the frame for a common agenda that is relevant to grassroots perspectives, national leaders and international actors.

- Introducing iterative approaches and adaptive management to ensure tight feedback loops between action, monitoring, learning and adapting.

- Developing an influence strategy and build a bigger coalition, getting more stakeholders on board

There is a vibrant literature on how to think and work politically. This query does not have time to go into this in depth. ${ }^{5}$ See also UN and World Bank (2017) for guidance on how to (re)build core government functions in FCAS by each domain.

\section{The resilience agenda}

Resilience thinking has emerged from the livelihoods and disaster risk and resilience literatures, and in more recent years, has become a core concept in the fields of peacebuilding, conflict sensitivity, and state-building. Resilience is now often seen as an important contributing factor to explain why some societies are particularly vulnerable to violence, while others experience protracted periods of peace (e.g. OECD, 2020, Menkhaus, 2013). This may herald a new fragility-to-resilience paradigm (Ingram \& Papoulidis, 2018; OECD, 2020).

Interpeace's concept of "resilience for peace", places conflict at the centre of its analysis, and understands resilience as: "the diverse endogenous attributes, capacities, resources and responses, that potentially enable individuals, communities, institutions and societies to deal peacefully with the impact of past conflict and violence, as well as to prevent new and emerging patterns of conflict and violence" (Simpson, Makoond, Vinck and Pham, 2016, p.9). A key understanding through this lens is that resilience, conflict, and peacebuilding have multiple connections, e.g. these include (McCandless and Nilus-Tarp, 2015, p.6; Simpson, et al., 2016; Fan, 2016):

- Conflict can be a distinct shock, stress, and risk that harms, decreases or undermines resilience directly and indirectly;

- Conflict can be a symptom of a lack of resilience;

- The intersection of conflict, disasters and fragility are manifold and can be mutually reinforcing;

- Resilient societies are better able to withstand the effects of conflict;

- Conflict can provoke a rupture in the system which can open up new opportunities for resilience (if and when there are capacities to transform);

- Peacebuilding can support and build resilience through strengthening the capacities of individuals, households, communities, states, etc, to absorb, adapt, and transform.

\footnotetext{
${ }^{55}$ E.g. further reading is recommended around the thinking and working politically (TWP) community, the Doing
} Development Differently community, and around political economy analysis thinking, etc. 


\section{Risk and vulnerability}

Resilience is directly shaped by the vulnerabilities and capacities that one has when facing a crisis - therefore risk analysis and preparedness is key. The resilience lens is proposed as a means to foster a more complex understanding of how risks emanating from disasters, conflict, and poverty interact and reinforce one another, and how to leverage resilient capacities for fragile political settlements (e.g. Ingram and Papoulidis, 2018; Opitz-Stapleton, Nadin, Kellett, Calderone, Quevedo, Peters, \& Mayhew, 2019; Fan, 2016). This means a move away from seeing conflict as the only or main risk, to understanding conflict as one among many complex, overlapping risks, a key finding from 10 years of Secure Livelihoods Research Consortium (SLRC) research (Papoulidis, 2021). This underlines the importance of conducting complex risk assessments (Papoulidis, 2021; Opitz-Stapleton, et al., 2019).

\section{Complexity}

Using resilience as a lens, rather than a label, reinforces the idea that resilience is not an endpoint, nor a certainty, or a clear binary category to be identified. This responds to the complexity agenda. And learns from the critiques of the failed state and fragile state agendas where those labels, the comparative indexes, and fragility lists arguably supported a too simplistic view of state fragility, lacking in nuance and context specificity (Lemay-Hébert, 2019). This agenda is also critiqued for overlooking the complex interplay of risk and capacity (Van Metre, 2016).

\section{Social capital}

Social capital, and social cohesion, are key concepts that underpin resilience. Social capital can be understood as having different dimensions (Downen, Mueller \& Frankenberger, 2019, p.3):

- Bonding social capital comprise the bonds between community members;

- Bridging social capital connects members of one community or group to other communities or groups; and

- Linking social capital is seen in trusted social networks between individuals and groups interacting across explicit, institutionalized, formal boundaries in society.

Ingram and Papoulidis (2018) note that incorporating social capital "as an organising principle into large-scale development programs, like the Afghanistan Basic Package on Health Services or Ethiopia's productive safety net, social capital can strengthen the norms and networks between fragmented communities and institutions to better mitigate risks and cope with crisis. When focused on greater empowerment and inclusion of women, social capital can increase their entry into wider markets and support peace efforts through bridging efforts across divided communities and links to formal institutions."

\section{Role of local communities}

The resilience lens has emerged from more bottom-up, participatory forms of development such as the livelihoods sector. Thus in the typically state-centric fragility agenda, it is considered to provide an important heuristic shift by refocusing attention on the positive attributes of states and societies and on the particular needs and capacities of local communities (Van 
Metre, 2016). Lessons from interventions in FCAS during the past decade demonstrate that donors have often focused on states and institutional capacities, rather than the realities of local communities. Rather than emphasising weakness, failure and fragility, resilience views the local and culture as a resource to be used positively in peacebuilding processes (Joseph \& Juncos, 2019). A key implication from ten years of SLRC research is that international actors need a greater understanding of the strength and type of coping capacities, with the commitment to better recognise and support existing coping capacities (Papoulidis, 2021).

In contexts like Somalia, where humanitarians, the private sector, and clan networks are longterm providers of basic services, state-building needs to be approached from top and bottom at the same time, without a default to community driven development only, finds Medinilla, et al. (2019). Indeed, Medinilla, et al. (2019) identify that "the real starting point for nexus approaches may well be at the local level".

While Ozano and Martineau (2018, p.3) highlight a positive example from Afghanistan when local partners were involved in needs assessments and decision-making processes on health programmes. This inclusion resulted in changes to "educational materials for rural populations, religious awareness in gender groupings for health educational interventions and recruitment of local staff, educated in languages and customs" (Ozano \& Martineau, 2018, p.3).

\section{Conceptual proliferation?}

Yet while the concepts of resilience, and 'building back better', are playing increasingly important roles in academic and policy literature, and in policymakers and practitioners thinking and practices, an important challenge is the limited consensus on how to define, understand, analyse, and operationalise it. Indeed, there are a large number of overlapping concepts that have linkages to resilience and conflict resilience within the broad security-developmenthumanitarian nexus. It is important to draw connections and lessons to ensure that the discussions about resilience move these debates forward, and that it does not just become another buzzword (Simpson, et al., 2016). While building resilience is increasingly seen as important in FCAS, it is a relatively new concept in this area, and thus work is needed to determine its added value from overlapping concepts (Runde \& Savoy, 2014). Work is also needed to translate it into action that is both politically and technically feasible for international actors (Herbert \& Marquette, 2021). Thus far, the resilience agenda is credited is having had "notable success" in managing major crises relating to food security and disaster risk reduction, however this has not yet been broadened to "promote country-wide resilience in the face of complex risks, which is precisely what is needed to exit fragility", argue Ingram and Papoulidis (2018).

\section{Prevention}

The resilience lens is being increasingly adopted in conflict prevention and stabilisation approaches, with important overlaps (Ingram and Papoulidis, 2018). E.g. the US Government's (2020) global fragility strategy puts a major emphasis on prevention and stabilisation, but it implicitly places both within a resilience framework

The prevention agenda can be understood as including approaches to avoid, minimise, and/or contain potential violent conflicts; and in post-conflict environments, to prevent violent conflict 
from re-emerging (Haider, 2014). Both conflict prevention and resilience building seek to identify risks (e.g. of an outbreak or relapse into conflict), and to reduce the vulnerabilities of certain actors or systems to those risks. Long term preventive institutions and mechanisms overlap with approaches adopted in the aftermath of conflict in order to prevent a renewal of violence (Haider, 2014); with peacebuilding approaches; and with the systemic transformation view of resilience.

Prevention efforts ideally comprise a continuum of mutually reinforcing actions, from early monitoring and action on risks, to consistent strengthening of social resilience (World Bank, 2018). Early warning systems - one among many tools for conflict prevention include: data collection, risk analysis, transmission of alert, recommendations, and monitoring and evaluation. They are used to design timely and appropriate conflict prevention initiatives, usually undertaken during latent stages of perceived potential conflict (Haider, 2014).

Coordination between civil society, local and national authorities, and international organisations is important so that warning signs can be detected and dealt with before they escalate. Local groups are well placed to identify early signs of violence (Saferworld, n.d.).

The flagship Pathways for Peace paper by the UN and World Bank (2018, p.236) connects the agendas by arguing that "preventing fragility, conflict and violence is central to reducing poverty and achieving shared prosperity" (p.xi, emphasis added), and that "addressing inequalities and exclusion, making institutions more inclusive, and ensuring that development strategies are risk-informed are central to preventing the fraying of the social fabric that could erupt into crisis" (UN \& World Bank, 2018, p.xviii).

An important element of the prevention agenda is the need for mechanisms to allow greater synergy "among the various tools and instruments of prevention, in particular, diplomacy and mediation, security, and development" (UN \& World Bank, 2018, p.xix). In terms of what has worked for managing contestation and preventing violent conflict, the UN and World Bank (2018, p.xix) highlight three areas: shaping the incentives of actors for peace, reforming institutions to foster inclusion, and addressing structural factors that feed into grievances.

The UN and World Bank (2018, p.xxv) identify three principles for prevention:

- Prevention must be sustained over time to address structural issues comprehensively, strengthen institutions, and adapt incentives for actors to manage conflict without violence. It should not be seen as a trade-off between the short and long term. This requires sustained investment in all risk environments, the integration of development investments into overarching strategies with politically viable short- and medium-term actions, and balancing resources so that action does not reward only crisis management

- Prevention must be inclusive and build broad partnerships across groups to identify and address grievances that fuel violence, while not focusing just on those that control the means of violence and positions of power. This highlights the importance of understanding people, their experiences, their communities, and the local context.

- Prevention must proactively and directly target patterns of exclusion and institutional weaknesses that increase risk. Successful prevention depends on proactive and targeted action before, during, and after violence. 
For better alignment between peace, security, and development actors, the UN and World Bank (2018, p.xxvi) recommend:

- Ensuring security and development approaches are compatible and mutually supportive

- Building capacity and allocating resources to ensure that grievances are mediated quickly and transparently

- Engaging actors beyond the state in platforms for dialogue and peacebuilding

- Adopting a people-centred approach

To overcome barriers to cooperation, the UN and World Bank (2018, p.xxvi) recommend:

- Sharing risk assessments

- Committing to collective mechanisms to identify and understand risks at regional, country, and subnational levels

- Ensuring that joint risk assessments articulate jointly agreed priorities

- Building stronger regional and global partnerships

- Exploring new investment approaches for prevention 


\section{References}

Barakat, S. \& Waldman, T. (2013). Conflict analysis for the twenty-first century. Conflict, Security \& Development, 13(3), 259-83

https://www.tandfonline.com/doi/abs/10.1080/14678802.2013.811048

Bertone, M. P., Jowett, M., Dale, E., \& Witter, S. (2019). Health financing in fragile and conflictaffected settings: What do we know, seven years on? Social Science \& Medicine, 232, 209-219. https://www.sciencedirect.com/science/article/pii/S0277953619302199

Deliver Accelerated Results Effectively and Sustainably (DARES) (2017) Deliver Accelerated Results Effectively and Sustainably: Operational Framework to Guide Collaboration in Fragile, Conflict and Vulnerable Settings. WHO, WFP, UNICEF \& World Bank. https://www.who.int/emergencies/partners/dares-operational-framework-nov17.pdf

DFID (2009). Building the State and Securing the Peace. Emerging Policy Paper. DFID http://www.gsdrc.org/docs/open/con64.pdf

Downen, J., Mueller, M., \& Frankenberger, T. (2019). Asia Resilience Review. TANGO International, Resilience Evaluation, Analysis and Learning (REAL) Associate Award. https://www.fsnnetwork.org/sites/default/files/Asia_Resilience_Review_2019_final508.pdf

Duffield, M. (2014). Global governance and the new wars: The merging of development and security. Zed Books Ltd.

Fan, L. (2016). Disasters, conflict, and fragility: A joint agenda. Working paper. Global facility for disaster reduction and recovery (GFDRR).

https://www.gfdrr.org/sites/default/files/documents/5.\%20Discussion\%20Paper\%20on\%20 Disasters\%2C\%20Conflict\%2C\%20and\%20Fragility.pdf

Food and Agriculture Organization (FAO), Development Initiatives (DI) \& Norwegian Refugee Council (NRC) (2021). Development actors at the nexus: Lessons from crises in Bangladesh, Cameroon and Somalia, synthesis report. FAO, DI \& NRC. https://doi.org/10.4060/cb3835en

Government of Central African Republic (2016). Central African Republic: National Recovery and Peacebuilding Plan 2017-21. Government of Central African Republic, EU, UN \& World Bank http://documents.worldbank.org/curated/en/817461516999933538/pdf/122994-WPPUBLIC-CAR-RPBA.pdf

Haider, H. (2014). Conflict: Topic Guide. Revised edition with B. Rohwerder. GSDRC, University of Birmingham. https://gsdrc.org/topic-guides/conflict/

Hearn, S. (2016). Independent review of the new deal for engagement in fragile states. Center on International Cooperation.

https://cic.nyu.edu/sites/default/files/new_deal_engagement_hearn_apr14_final.pdf

Herbert, S. \& Marquette, H. (2021). COVID-19, governance, and conflict: emerging impacts and future evidence needs. K4D Emerging Issues Report 34. Institute of Development Studies. 
DOI: 10.19088/K4D.2021.0291

https://opendocs.ids.ac.uk/opendocs/handle/20.500.12413/16477

Herbert, S. (2014). Sequencing reforms in fragile states: Topic guide. GSDRC, University of Birmingham. https://gsdrc.org/topic-guides/sequencing-reforms-in-fragile-states/

Hinds, R. (2015). Relationship between humanitarian and development aid (GSDRC Helpdesk Research Report 1185). GSDRC, University of Birmingham http://www.gsdrc.org/docs/open/hdq1185.pdf

Ingram, G. \& Papoulidis, J. (2018) Fragile states and the search for 'what works'. [Blog] Brookings Institute. https://www.brookings.edu/blog/future-development/2018/11/08/fragilestates-and-the-search-for-what-works/

International Council of Voluntary Agencies (ICVA) (2017). The "New Way Of Working" examined. Briefing paper. ICVA. https://www.icvanetwork.org/resources/new-way-workingexamined-icva-briefing-paper

Joseph, J., \& Juncos, A. E. (2019). A promise not fulfilled: The (non) implementation of the resilience turn in EU peacebuilding. Contemporary Security Policy, 1-24. https://doi.org/10.1080/13523260.2019.1703082

Lemay-Hébert, N. (2019) From Saving Failed States to Managing Risks: Reinterpreting Fragility through Resilience. In Lahai, J., I., von Strokirch, K., Brasted, H. and Ware, H. (Eds.) Governance and Political Adaptation in Fragile States. Palgrave Macmillan. ISBN 978-3319-90749-9.

Lindborg, N. (2017). Handle with care: The challenge of fragility. Brookings Institution. https://www.brookings.edu/research/handle-with-care-the-challenge-of-fragility/

Manuel, M., McKechnie, A., Wilson, G., \& das Pradhan-Blach, R. (2017). The new deal in Somalia: An independent review of the Somali Compact 2014-2016. ODI. www.odi.org/publications/10786-new-deal-somalia-independent-review-somali-compact2014-2016

McCandless, E. and Nilaus-Tarp, K. (2015) The Contribution of Social Services to Peacebuilding and Resilience: Evolving Theory and Practice. United Nations Children's Fund (UNICEF) http://www.erinmccandless.net/uploads/3/1/5/5/31558725/the_contribution_of_social_servi ces_to_peacebuilding_and_resilience_-_unicef_study_final.pdf

Medinilla, A., Shiferaw, L. T., \& Veron, P. (2019). Think local. Governance, humanitarian aid, development and peacebuilding in Somalia Discussion Paper (No. 246). ECDPM https://ecdpm.org/publications/think-local-bridging-between-humanitarian-aid-developmentpeacebuilding-somalia/

Menkhaus, K. (2013) Making Sense of Resilience in Peacebuilding Contexts: Approaches, Applications, Implications. Geneva Peacebuilding Platform https://www.gpplatform.ch/sites/default/files/PP\%2006\%20\%20Resilience\%20to\%20Transformation\%20-\%20Jan.\%202013_3.pdf

OECD (2020) States of Fragility 2020. OECD. https://doi.org/10.1787/ba7c22e7-en 
Opitz-Stapleton, S., Nadin, R., Kellett, J., Calderone, M., Quevedo, A., Peters, K., \& Mayhew, L. (2019). Risk-informed development: from crisis to resilience. ODI

https://odi.org/en/publications/risk-informed-development-from-crisis-to-

resilience/\#: :text=Risk\%2Dinformed\%20development\%20is\%20a,risks\%2C\%20as\%20we II\%20as\%20opportunities

Ozano, K. \& Martineau, T. (2018). Responding to humanitarian crises in ways that strengthen longer-term health systems: What do we know? Brief. ReBUILD Consortium, Liverpool School of Tropical Medicine https://rebuildconsortium.com/media/1607/rebuild_briefing_9_july_18_health_systems.pdf

Papoulidis, J. (2020a) Country Platforms in Fragile States: A New Path for Development Cooperation. [Blog] Global Delivery Initiative http://www.globaldeliveryinitiative.org/blogs/country-platforms-fragile-states-new-pathdevelopment-cooperation

Papoulidis, J. (2020b) Opinion: Time to rethink development finance in fragile states. [Blog] Devex. https://www.devex.com/news/opinion-time-to-rethink-development-finance-infragile-states-96647

Papoulidis, J. (2021) Three things SLRC teaches us about supporting a shift from fragility to resilience. Briefing Paper. Secure Livelihoods Research Consortium, Overseas Development Institute (ODI) https://securelivelihoods.org/wp-content/uploads/SLRCFragilityToResilence-Papoulidis-BP-Mar21-Proof03.pdf

Runde, D.F. and Savoy, C.M. (2014). Resilience: A critical framework for development. Centre for Strategic and International Studies (CSIS). https://www.csis.org/analysis/resiliencecritical-framework-development

Saferworld (n.d.). Capacities for peace project. Saferworld. https://www.saferworld.org.uk/projects/capacities-for-peace-project

Saferworld (2011). The securitisation of aid? Briefing. Saferworld. https://www.saferworld.org.uk/resources/publications/505

Simpson, G., Makoond, A., Vinck, P. \& Pham, P.N. (2016). Assessing resilience for peace: Guidance note. Interpeace. http://www.interpeace.org/wp-content/uploads/2016/06/2016FAR-Guidace-note-Assesing-Resilience-for-Peace-v7.pdf

Stoddard, A. \& Harmer, A. (2005). Room to manoeuvre: Challenges of linking humanitarian action and post conflict recovery in the new security environment. UNDP https://gsdrc.org/document-library/room-to-manoeuvre-challenges-of-linking-humanitarianaction-and-post-conflict-recovery-in-the-new-security-environment/

Thier, J. A. (2019). Transforming fragile states. ODI. https://odi.org/en/publications/transformingfragile-states-forging-a-new-consensus/

UN \& World Bank (2017) (Re)Building Core Government Functions in Fragile and Conflict Affected Settings: Joint Principles for Assessing Key Issues and Priorities. UN \& World Bank 
https://www.undp.org/content/dam/undp/library/Democratic\%20Governance/Public\%20Ad ministration/rebuilding\%20core\%20government\%20functions\%20joint\%20principles.pdf

UN (n.d.) The New Way of Working. [Webpage] UN. Accessed 10 May 2021 https://www.un.org/jsc/content/new-way-working

United Nations (UN) \& World Bank (2018) Pathways for Peace. United Nations (UN) \& World Bank. https://www.pathwaysforpeace.org/

UNOCHA (2018). COLLECTIVE OUTCOMES: Operationalizing the New Way of Working. UNOCHA.

http://www.agendaforhumanity.org/sites/default/files/resources/2018/Apr/OCHA\%20Collect ive\%200utcomes\%20April\%202018.pdf

US Government (2020) United States Strategy to Prevent Conflict and Promote Stability. US Government https://state.gov/wp-content/uploads/2019/07/Strategic-Prevention-Project.pdf

Van Metre, L. (2016). Fragility and Resilience. Fragility Study Group. Policy Brief. United States Institute of Peace (USIP). https://css.ethz.ch/content/dam/ethz/specialinterest/gess/cis/center-for-securities-studies/resources/docs/USIPFragility\%20and\%20Resilience.pdf

Witter, S., Falisse, J. B., Bertone, M. P., Alonso-Garbayo, A., Martins, J. S., Salehi, A. S., Pavignani, E. \& Martineau, T. (2015). State-building and human resources for health in fragile and conflict-affected states: exploring the linkages. Human resources for health, 13(1), 1-15. https://human-resources-health.biomedcentral.com/articles/10.1186/s12960015-0023-5

World Bank Group. (2017). Social service delivery in violent contexts: achieving results against the odds-a report from Afghanistan, Pakistan and Nepal. World Bank.

https://documents.worldbank.org/en/publication/documentsreports/documentdetail/343141497021595501/social-service-delivery-in-violent-contextsachieving-results-against-the-odds-a-report-from-afghanistan-pakistan-and-nepal

\section{Acknowledgements}

We thank the following experts who voluntarily provided suggestions for relevant literature or other advice to the author to support the preparation of this report. The content of the report does not necessarily reflect the opinions of any of the experts consulted.

- Jonathan Papoulidis (Columbia World Projects \& World Vision)

- Seth Kaplan (SAIS/Johns Hopkins University)

- Andre Griekspoora (World Health Organization)

- Rajia Sharhan (UNICEF)

- Maria Bertone (Queen Margaret University)

- Sophie Witter (Queen Margaret University)

- Karin Diaconu (Queen Margaret University) 


\section{Suggested citation}

Herbert, S. (2021). Maintaining basic state functions and service delivery during escalating crises. K4D Helpdesk Report. Institute of Development Studies. DOI: 10.19088/K4D.2021.099

\section{About this report}

This report is based on six days of desk-based research. The K4D research helpdesk provides rapid syntheses of a selection of recent relevant literature and international expert thinking in response to specific questions relating to international development. For any enquiries, contact helpdesk@k4d.info.

K4D services are provided by a consortium of leading organisations working in international development, led by the Institute of Development Studies (IDS), with the Education Development Trust, Itad, University of Leeds Nuffield Centre for International Health and Development, Liverpool School of Tropical Medicine (LSTM), University of Birmingham International Development Department (IDD) and the University of Manchester Humanitarian and Conflict Response Institute (HCRI).

This report was prepared for the UK Government's Foreign, Commonwealth \& Development Office (FCDO) and its partners in support of pro-poor programmes. Except where otherwise stated, it is licensed for non-commercial purposes under the terms of the Open Government Licence v3.0. K4D cannot be held responsible for errors or any consequences arising from the use of information contained in this report. Any views and opinions expressed do not necessarily reflect those of FCDO, K4D or any other contributing organisation.

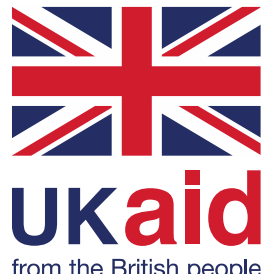

(c) Crown copyright 2021 